\title{
Chitosan and chitooligosaccharide utilization in phytoremediation and biofortification programs: current knowledge and future perspectives
}

\author{
Marta W. Vasconcelos* \\ CBQF - Centro de Biotecnologia e Química Fina - Laboratório Associado, Escola Superior de Biotecnologia, Universidade Católica Portuguesa/Porto, Porto, \\ Portugal \\ *Correspondence: mvasconcelos@porto.ucp.pt
}

Edited by:

David W. M. Leung, University of Canterbury, New Zealand

Reviewed by:

Dharmendra Kumar Gupta, Estación Experimental del Zaidín-Consejo Superior de Investigaciones Científicas, Spain

Keywords: biofortification, chitooligosaccharide, chitosan, mineral, phytoremediation

\section{INTRODUCTION}

Chitosans and chitooligosaccharides (CHOS) are polysaccharides with a broad range of applications, including plant growth promoting activities. Both compounds have also been shown to have metal chelating properties. However, several factors, such as degree of polymerization, degree of deacetylation, $\mathrm{pH}$, temperature, concentration, application method, viscosity and purity, can influence chitosan and CHOS mode of action. Most applications of chitosans and CHOS so far have been in the biomedical industry. But given that there is a great interested to find novel ways to enhance the plant's nutritional value (biofortification) or to modulate the capacity of plants to extract toxic metals from the soil (phytoremediation), a better understanding of chitosan and CHOS effects in plant systems is warranted.

\section{WHAT ARE CHITOSANS AND CHOS?}

Before discussing the possible applications of these molecules, it is important to clarify what they are. Chitin, chitosans and $\mathrm{CHOS}$ are three inter-related compounds of polysaccharidic nature. Chitin was first isolated in 1811 (Domard and Domard, 2002), and it is the second most important biopolymer in the world after cellulose (Rinaudo, 2006). Even though its first isolation was in mushrooms, chitin has since been obtained from many other sources, including cell walls of several yeast and fungal strains and from the exoskeleton of crawfish, shrimp and crabs. It is composed of a long-chain homopolymer of $\mathrm{N}$-acetyl-D-glucosamine (GlcNAc), (1-4)-linked 2-acetamido-2deoxy- $\beta$-D-glucan (Park and Kim, 2010) and is insoluble in water, limiting its utilization in living systems (Park and Kim, 2010). It can, however be broken down into other molecules with higher solubility. Chitosan is one of such molecules. It is at least $50 \%$ deacetilated and it is aqueous in acidic media (Rinaudo, 2006; Aam et al., 2010). CHOS have a degree of polymerization higher than $20 \%$ and an average molecular weight less than $3900 \mathrm{Da}$ (Lodhi et al., 2014). Still, chitosans and CHOS can be very diverse in several features such as (i) sequence, (ii) degree and pattern of $\mathrm{N}$-acetylation; (iii) fraction of $\mathrm{N}$-acetylated residues; (iv) degree of polymerization; (v) molecular weight, and polydispersity. This vast degree of compositional variability is in fact one of the major obstacles in chitosan research. Comprehensive knowledge on their modeof-action is still scarce, because most published studies are done with heterogeneous mixtures and because production of well-defined chitosans and CHOS is not easily done (Montilla et al., 2013). Further, chitosan is easily degraded into CHOS by naturally occurring hydrolytic enzymes in most living systems, including plants. Thus, some of the attributed functions to chitosans may in fact be due to CHOS. Despite these issues, there has been a recent interest in using these compounds to stimulate plant growth (AbuMuriefah, 2013) and to modulate plant mineral concentrations (Chatelain et al., 2014).

\section{CAN THEY BE USED FOR PHYTOREMEDIATION OR BIOFORTIFICATION?}

The most commonly reported utilizations of chitosans and CHOS have been in the human biomedical industry (Park and Kim, 2010), as both compounds seem to possess medicinal properties (Mourya et al., 2011). On the other hand, the applications of CHOS and chitosan in plant science have been less diverse, and mostly linked to their antimicrobial activity. Both molecules are known to induce the biosynthesis of several antimicrobial compounds, namely phytoalexins (Vasyukova et al., 2001), callose (Ren et al., 2001) and lignin (Barber et al., 1989). Several papers have reported that chitosans and $\mathrm{CHOs}$ can be used, for example, to enhance the plant's defense against bacteria (Tikhonov et al., 2006; Rabea and Steurbaut, 2010), fungi (Park et al., 2002; Trotel-Aziz et al., 2006) and nematodes (Khalil and Badawy, 2012; Nunes da Silva et al., 2014). Besides plant defense, a broader range of influences in plant growth and development have been shown. They have also been used to augment foliar biomass in lettuce (Benavides-Mendoza et al., 2001), promote shoot and root growth in Daikon radish (Tsugita et al., 1993), hasten flowering time and increase flower number in passion fruit (Utsunomiya and Kinai, 1994), promote in vitro growth of cabbage (Hirano, 1988), enhance growth and hastened flowering time of Eustoma grandiflorum (Ohta et al., 1999), and alleviate iron deficiency chlorosis (IDC) symptoms in soybean (Vasconcelos, unpublished data). Abu-Muriefah (2013) suggested that 
foliar application of chitosan could be a promising strategy to reduce water stress symptoms in common bean, having positive effects in terms of growth and yield. When applied hydroponically, CHOS can also alter root length, mineral accumulation and shoot biomass in common bean (Chatelain et al., 2014) (Figure 1).

It is possible that these positive effects may be linked to the ability of chitosans and CHOS to chelate minerals and other nutrients, making them more available for uptake by the plant. This is important, since crop production is many times limited by low phytoavailability of essential mineral elements (White and Brown, 2010). In fact, the capacity of chitosans and CHOS to chelate certain ions makes them interesting compounds to be used in phytoremediation strategies. For example, mechanically disassembled chitosan nanofibrils have been used as metal ion chelating agents (Liu et al., 2014), and were effective chelating agents for copper $(\mathrm{Cu})$, lead $(\mathrm{Pb})$ and cadmium (Cd). Similarly, chitin in the form of micro-particles in solution showed a good sorption capacity for $\mathrm{Cd}$, nickel $(\mathrm{Ni}), \mathrm{Cu}$, zinc $(\mathrm{Zn}), \mathrm{Pb}$ and chromium (Cr) (Liu et al., 2013), suggesting their use for heavy metal treatment. Chen et al. (2011) reported on the successful biosorption of $\mathrm{Cu}, \mathrm{Zn}, \mathrm{Ni}$, and $\mathrm{Pb}$ ions by cross-linked metal-imprinted chitosans and suggested their use for metal removal. Recently, an innovative bioremediation strategy using a bacterial consortium entrapped in chitosan beads was developed for oil-contaminated mangrove sediments (Angelim et al., 2013), showing promising results.

In 2011, Kamari et al. (2011a) showed that chitosans could bind silver (Ag), $\mathrm{Zn}$, $\mathrm{Cd}$, and $\mathrm{Pb}$. In this same study they concluded that the main binding mechanism of chitosans to the metals was via their functional groups (amino and hydroxyl), and that even at very high dilution rates, the chitosans were able to retain metal ions on their surfaces. They also showed, in a separate study, that remediation of metal contaminated soil using chitosan and cross-linked treated chitosans as soil amendments is feasible (Kamari et al., 2011b). The following year, in a greenhouse pot experiment, Kamari et al. (2012) reported on the impact of chitosan application on metal accumulation in Lolium perenne (perennial ryegrass) and Brassica napus (rapeseed).

Heavy metals and beneficial minerals share many regulatory mechanisms for absorption, translocation and accumulation (Clemens et al., 2013). Thus, if chitosans and CHOS can help plants take up higher concentrations of toxic elements, it is possible that they can also increase absorption of essential minerals. Plants require 14 elements for their nutrition: nitrogen $(\mathrm{N})$, phosphorus $(\mathrm{P})$, potassium $(\mathrm{K})$, calcium $(\mathrm{Ca})$, magnesium $(\mathrm{Mg})$ sulfur $(\mathrm{S})$, chlorine $(\mathrm{Cl})$, boron $(\mathrm{B})$, iron $(\mathrm{Fe})$, manganese $(\mathrm{Mn}), \mathrm{Cu}, \mathrm{Zn}, \mathrm{Ni}$, and molybdenum (Mo). Some of these are known to be adsorbed by chitosans and CHOS, forming interesting chelator complexes with these elements. Fe and $\mathrm{Zn}$ are two of the most important mineral elements whose dietary deficiency affects more than $30 \%$ of the world's population (Vasconcelos et al., 2003), thus an impact on the accumulation of these two elements would be particularly important.

Given the promising results of chitosans and $\mathrm{CHOS}$ at chelating toxic

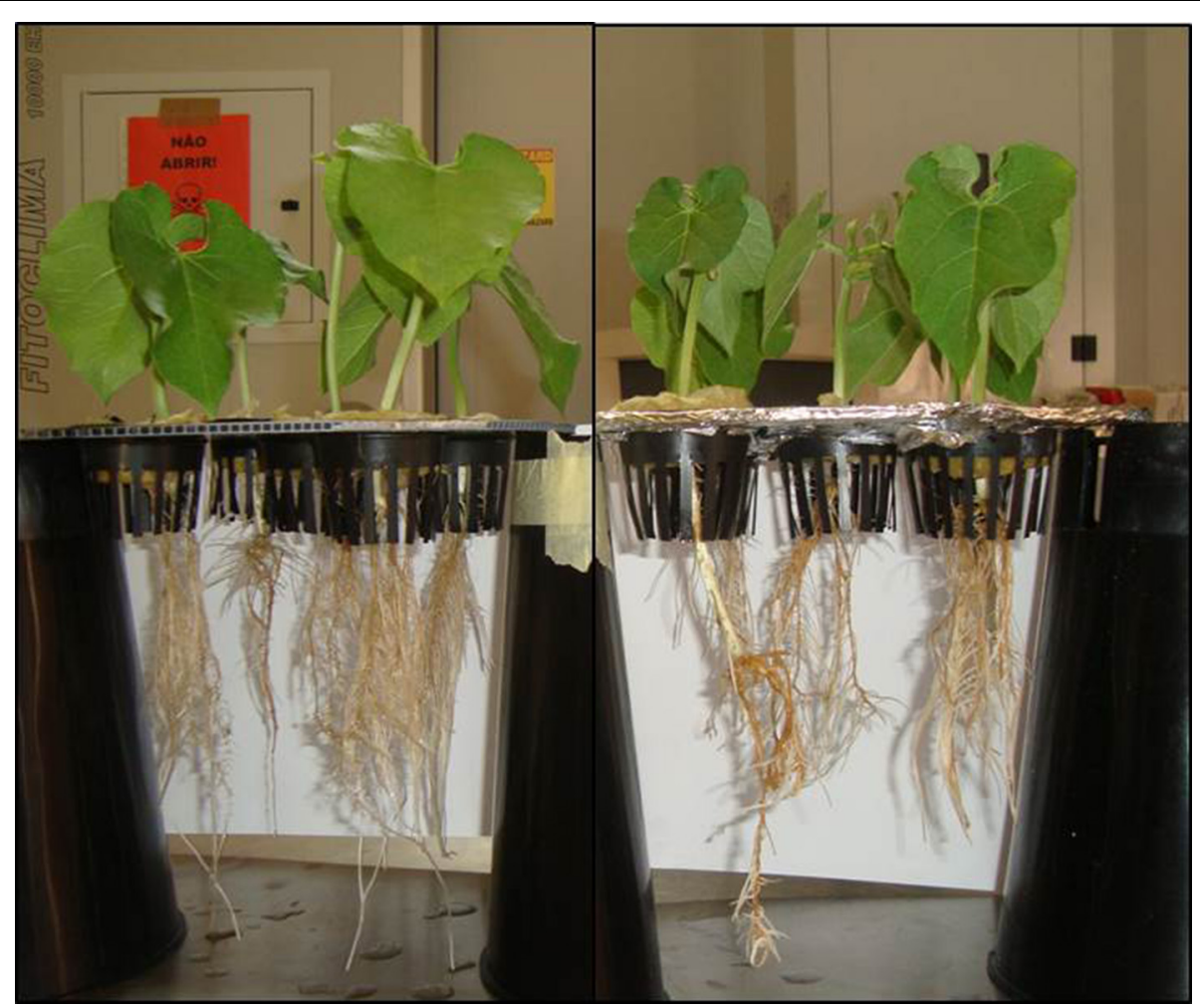

FIGURE 1 | Common bean ( $P$ vulgaris L.) plants grown 12 days hydroponically without (left) or with (right) $0.01 \mathrm{~g} / \mathrm{L} \mathrm{CHOS.}$ 
minerals, and since heavy metals oftentimes share, as stated before, common assimilation pathways with beneficial minerals, it is possible that chitosans and $\mathrm{CHOS}$ could have an application in biofortification programs. However, despite the relatively large amount of studies on bioremediation, very few studies so far have validated the use of either chitosan or CHOS in modulating metal uptake, transport and storage in plants, namely for phytoremediation purposes. Recently, we conducted a hydroponic experiment supplying different types of CHOS to Phaseolus vulgaris, and we looked at mineral accumulation potential for both beneficial and toxic metals (Mo, B, Zn, P, $\mathrm{Pb}, \mathrm{Cd}, \mathrm{Mn}, \mathrm{Fe}, \mathrm{Mg}, \mathrm{Ca}, \mathrm{Cu}, \mathrm{Na}, \mathrm{Al}$, and $\mathrm{K})$ in leaves, stems and roots (Chatelain et al., 2014). Our results showed a high variability in metal concentration with regards to tissue type and CHOS concentration. Also, despite observing positive effects, for example for $\mathrm{K}$ and $\mathrm{Ca}$, we also observed no alterations in concentration for other elements, or even a reduction in accumulation. One downfall was that we observed toxicity of CHOS when applied at higher doses, which could be related to changes in anatomical features of the roots (Figure 1).

If targeting biofortification, the right dosage of chitosan or CHOS must be carefully chosen, and experiments must be addressed over the entire plant life cycle. However, there is no available study looking at the effect of chitosans or CHOS on seed minerals. Given the evidence thus far, this would be an interesting avenue to investigate, but scientists must be very careful when designing the experiment, as considerations of toxicity must be taken into account. Also, it is important to utilize very well characterized types of chitosans or CHOS, because their chemical composition will impact their structure and solubility. This, in turn, will directly influence their availability, stability and permanence in solution or soil matrixes.

Currently, no comprehensive studies are available on the changes on chitosan structure in the soil, but it is very likely that it will undergo major conformational and structural changes depending on soil pH. It is well known that chitosan is only soluble in acidic conditions, thus in alkaline soils, which account for $30 \%$ of total arable land, it would probably be poorly available for plant utilization. Also, it is necessary to understand if the chitosan:mineral and CHOS:mineral complex can actually enter the plant and deliver the minerals to edible plant parts, such as shoots and roots. The mobility of the complex in the plants vascular system has not been demonstrated yet, and it would provide some valuable information on the potential of this special class of molecules on depleting toxic metals from the soil, or enhancing favorable mineral accumulation by the plant.

In any case, there is enough compelling evidence that chitosans and CHOS have an impact on plant growth and development, probably due to their chelating capacities, making them more or less available to the plant. Perhaps better vehicles for delivery can be designed, similarly to the ones used for biomedical applications, before the real impact of chitosans or CHOS on plant nutrition and health can be maximized.

\section{ACKNOWLEDGMENTS}

This work was supported by National Funds from Fundação para a Ciência e a Tecnologia (FCT) through project PEst-OE/EQB/LA0016/2013 and from PTDC/AGR-GPL/118772/2010.

\section{REFERENCES}

Aam, B. B., Heggset, E. B., Norberg, A. L., Sørlie, M., Vårum, K. M., and Eijsink, V. G. (2010). Production of chitooligosaccharides and their potential applications in medicine. Mar. Drugs 8, 1482-1517. doi: 10.3390/md8051482

Abu-Muriefah, S. S. (2013). Effect of chitosan on common bean (Phaseolus vulgaris L.) plants grown under water stress conditions. Int. Res. J. Agric. Sci. Soil Sci. 3: 192-199.

Angelim, A. L., Costa, S. P., Farias, B. C., Aquino, L. F., and Melo, V. M. (2013). An innovative bioremediation strategy using a bacterial consortium entrapped in chitosan beads. J. Environ. Manage. 127, 10-17. doi: 10.1016/j.jenvman.2013.04.014

Barber, M. S., Bertram, R. E., and Ride, J. P. (1989). Chitin oligosaccharides elicit lignifications in wounded wheat leaves. Physiol. Mol. Plant Pathol. 34, 3-12. doi: 10.1016/0885-5765(89)90012-X

Benavides-Mendoza, A., Romero-García, J., LedesmaPérez, A. S., and Raygoza-Castro, J. M. (2001). La aplicación foliar de quitosano en ácido acético aumenta la biomasa de la lechuga. BIOTAM Nueva Ser. 12, 1-6.

Chatelain, P. G., Pintado, M. E., and Vasconcelos, M. W. (2014). Evaluation of chitooligosaccharide application on mineral accumulation and plant growth in Phaseolus vulgaris. Plant Sci. 215-216, 134-140. doi: 10.1016/j.plantsci.2013.11.009

Chen, C. Y., Yang, C. Y., and Chen, A. H. (2011). Biosorption of $\mathrm{Cu}(\mathrm{II}), \mathrm{Zn}(\mathrm{II}), \mathrm{Ni}(\mathrm{II})$ and $\mathrm{Pb}(\mathrm{II})$ ions by cross-linked metal-imprinted chitosans with epichlorohydrin. J. Environ. Manage. 92, 796-802. doi: 10.1016/j.jenvman.2010.10.029

Clemens, S., Aarts, M. G., Thomine, S., and Verbruggen, N. (2013). Plant science: the key to preventing slow cadmium poisoning. Trends Plant Sci. 18, 92-99. doi: 10.1016/j.tplants.2012.08.003

Domard, A., and Domard, M. (2002). Chitosan: structure properties relationship and biomedical applications. Polym. Biomater. 9, 187-212. doi: 10.1201/9780203904671.ch9

Hirano, S. (1988). The activation of plant cells and their self-defence function against pathogens in connection with chitosan (in Japanese with English summary). Nippon Nogeikagaku kaishi 62, 293-295. doi: 10.1271/nogeikagaku1924.62.1238

Kamari, A., Pulford, I. D., and Hargreaves, J. S. (2011a). Chitosan as a potential amendment to remediate metal contaminated soil - a characterisation study. Colloids Surf. B Biointerfaces. 82, 71-80. doi: 10.1016/j.colsurfb.2010.08.019

Kamari, A., Pulford, I. D., and Hargreaves, J. S. (2011b). Binding of heavy metal contaminants onto chitosans-an evaluation for remediation of metal contaminated soil and water. J. Environ. Manage. 92, 2675-2682. doi: 10.1016/j.jenvman.2011.06.005

Kamari, A., Pulford, I. D., and Hargreaves, J. S. (2012). Metal accumulation in Lolium perenne and Brassica napus as affected by application of chitosans. Int. J. Phytorem. 14, 894-907. doi: 10.1080/15226514.2011.636401

Khalil, M. S., and Badawy, M. E. (2012). Nematicidal activity of a biopolymer chitosan at different molecular weights against root-knot nematode, Meloidogyne incognita. Plant Protect Sci. 48, 170-178.

Liu, D., Li, Z., Zhu, Y., Li, Z., and Kumar, R. (2014). Recycled chitosan nanofibril as an effective $\mathrm{Cu}(\mathrm{II})$, $\mathrm{Pb}$ (II) and $\mathrm{Cd}$ (II) ionic chelating agent: adsorption and desorption performance. Carbohydr. Polym. 111, 469-476. doi: 10.1016/j.carbpol.2014. 04.018

Liu, D., Zhu, Y., Li, Z., Tian, D., Chen, L., and Chen, P. (2013). Chitin nanofibrils for rapid and efficient removal of metal ions from water system. Carbohydr. Polym. 98, 483-489. doi: 10.1016/j.carbpol.2013.06.015

Lodhi, G., Kim, Y.-S., Hwang, J.-W., Kim, S.-K., Jeon, Y.-J., Je, J.-Y., et al. (2014). Chitooligosaccharide and Its Derivatives: preparation and biological applications. Biomed Res. Int. 2014:654913. doi: $10.1155 / 2014 / 654913$

Montilla, A., Ruiz-Matute, A. I., Corzo, N., Giacomini, G., and Irazoqui, G. (2013). Enzymatic generation of chitooligosaccharides from chitosan using soluble and immobilized glycosyltransferase (Branchzyme). J. Agric. Food Chem. 61, 10360-10367. doi: 10.1021/jf403321r

Mourya, V. K., Inamdar, N. N., and Choudhari, Y. M. (2011). Chitooligosaccharides: synthesis, characterization and applications. Polym. Sci. Ser. A 53, 583-612. doi: 10.1134/S0965545X11070066

Nunes da Silva, M., Cardoso, A. R., Ferreira, D., Brito, M., Pintado, M. E., and Vasconcelos, 
M. W. (2014). Chitosan as a biocontrol agent against the pinewood nematode (Bursaphelenchus xylophilus). Plant Pathol. 62, 1398-1406. doi: 10.1111/ppa.12037

Ohta, K., Taniguchi, A., Konishi, N., and Hosoki, T. (1999). Chitosan treatment affects plant growth and flower quality in Eustoma grandiflorum. Hortic. Sci. 34, 233-234.

Park, B. K., and Kim, M.-M. (2010). Applications of chitin and its derivatives in biological medicine. Int. J. Mol. Sci. 11, 5152-5164. doi: 10.3390/ijms11125152

Park, R. D., Jo, K. J., Jo, Y. Y., Jin, Y. L., Kim, K. Y., Shim, J. H., et al. (2002). Variation of antifungal activities of chitosans on plant pathogens. J. Microbiol. Biotechnol. 12, 84-88.

Rabea, E. I., and Steurbaut, W. (2010). Chemically modified chitosans as antimicrobial agents against some plant pathogenic bacteria and fungi. Plant Protect. Sci. 46, 149-158.

Ren, H., Endo, H., and Hayashi, T. (2001). Antioxidative and antimutagenic activities and polyphenol content of pesticide-free and organically cultivated green vegetable using water-soluble chitosan as a soil modifier and leaf surface spray. J. Sci. Food Agric. 81, 1426-1432. doi: 10.1002/jsfa.955

Rinaudo, M. (2006). Chitin and chitosan: properties and applications. Prog. Polym. Sci. 31, 603-632. doi: 10.1016/j.progpolymsci.2006.06.001
Tikhonov, V. E., Stepnova, E. A., Babak, V. G., Yamskov, I. A., Palma-Guerrero, J., Jansson, H. B., et al. (2006). Bactericidal and antifungal activities of a low molecular weight chitosan and its $\mathrm{N}-/ 2(3)$-(dodec-2-enyl)succinoyl/derivatives. Carbohydr. Polym. 64, 66-72. doi: 10.1016/j.carbpol.2005.10.021

Trotel-Aziz, P., Couderchet, M., Vernet, G., and Aziz, A. (2006). Chitosan stimulates defense reactions in grapevine leaves and inhibits development of Botrytis cinerea. Eur. J. Plant Pathol. 114, 405-413. doi: 10.1007/s10658-006-0005-5

Tsugita, T., Takahashi, K., Muraoka, T., and Fukui, H. (1993). "The application of chitin/chitosan for agriculture (in Japanese)," in Proc. Spec. Session 7th Symp. on Chitin and Chitosan, Jpn. Soc. for Chitin and Chitosan, (Fukui). 21-22.

Utsunomiya, N., and Kinai, H. (1994). Effect of chitosan-oligosaccharides soil conditioner on the growth of passionfruit (in Japanese). J. Jpn. Soc. Hort. Sci. 64, 176-177.

Vasconcelos, M., Datta, K., Oliva, N., Khalekuzzaman, M., Torrizo, L., Krishnan, S., et al. (2003). Enhanced iron and zinc accumulation in transgenic rice with the ferritin gene. Plant Sci. 164, 371-378. doi: 10.1016/S0168-9452(02)00421-1

Vasyukova, N. I., Zinov'eva, S. V., Il'inskaya, L. I., Perekhod, E. A., Chalenko, G. I., Gerasimova, N. G., et al. (2001). Modulation of plant resistance to diseases by watersoluble chitosan.
Appl. Biochem. Microbiol. 37, 103-109. doi: 10.1023/A:1002865029994

White, P. J., and Brown, P. H. (2010). Plant nutrition for sustainable development and global health. Ann. Bot. 105, 1073-1080. doi: 10.1093/aob/mcq085

Conflict of Interest Statement: The author declares that the research was conducted in the absence of any commercial or financial relationships that could be construed as a potential conflict of interest.

Received: 14 August 2014; accepted: 21 October 2014; published online: 12 November 2014.

Citation: Vasconcelos MW (2014) Chitosan and chitooligosaccharide utilization in phytoremediation and biofortification programs: current knowledge and future perspectives. Front. Plant Sci. 5:616. doi: 10.3389/fpls. 2014.00616

This article was submitted to Plant Biotechnology, a section of the journal Frontiers in Plant Science.

Copyright (c) 2014 Vasconcelos. This is an open-access article distributed under the terms of the Creative Commons Attribution License (CC BY). The use, distribution or reproduction in other forums is permitted, provided the original author(s) or licensor are credited and that the original publication in this journal is cited, in accordance with accepted academic practice. No use, distribution or reproduction is permitted which does not comply with these terms. 